\title{
Erratum to: Asymptotic Analysis of the Plane Strain State Generated by a Finite Longitudinal Shear Crack
}

\author{
A. Shariati ${ }^{1 *}$, A. H. Shamekhi ${ }^{2}$, A. Ghaffari ${ }^{2}$, S. Gholampour ${ }^{3}$, and K. Motaghed A. ${ }^{4 * *}$ \\ ${ }^{1}$ Department of Mechanical Engineering, University College London, London, UK \\ ${ }^{2}$ Department of Mechanical Engineering, K.N. Toosi University of Technology, Tehran, Iran \\ ${ }^{3}$ Department of Biomedical Engineering, North Tehran Branch, Islamic Azad University, Tehran, Iran \\ ${ }^{4}$ Department of Aerospace Engineering, Sharif University of Technology, Tehran, Iran \\ Received September 1, 2019; revised September 10, 2019; accepted September 16, 2019
}

DOI: $10.3103 / \mathrm{S} 0025654419060141$

There was a mistake in the author mane. The right fifth author is "K. Motaghed A."

There was a mistake in the first keyword. The keyword is "Two-wheeled inverted pendulum (TWIP)."

The original article can be found online at https://doi.org/10.3103/S0025654419040162.

*e-mail: a.shariati@ucl.ac.uk

** e-mail: kamyar_motaghed@alumn. sharif .edu 